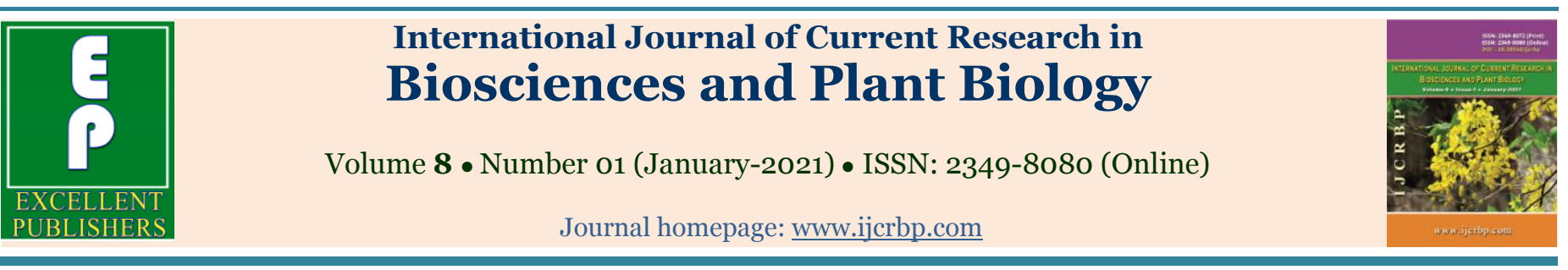

\title{
Prevalence, inventory and characterization of different morphotypes of Fusarium spp. associated with spoilage of tomato fruits (Solanum lycopersicum L.) in the west-region of Cameroon
}

\author{
Desiré Njimah Mfonmbouot ${ }^{\circledR}$, Gaston R. Tsopmbeng Noumbo ${ }^{1}$, Stephen Lacmata \\ Tamekou $\mathbb{D}^{2}$, Elie Keuete Kamdoum ${ }^{1}$, Jules-Roger Kuiate ${ }^{\left(D^{2}\right.}{ }^{2}$
${ }^{1}$ Research Unit of Applied Botany, Faculty of Science, University of Dschang, P.O. Box 67 Dschang, Cameroon
${ }^{2}$ Research Unit of Microbiology and Antimicrobial Substances, Faculty of Science, University of Dschang, \\ P.O. Box 67 Dschang, Cameroon
}

*Corresponding author; e-mail: jrkuiate@yahoo.com

\begin{abstract}
Article Info
Keywords:

Characterization

Fusarium spp.

Inventory

Prevalence

Tomato fruit

Abstract

Fusariosis is one of the diseases that cause many pre- and post-harvest losses of tomato fruits. This disease is caused by fungi belonging to the genus Fusarium spp. The present study was carried out to determine the prevalence of Fusariosis in the major tomato fruit production basins in West Cameroon, to inventory and characterize the different Fusarium spp. morphotypes associated with this tomato fruit rot. To achieve this objective, the prevalence of these fruit rots was determined in each production basins. The different morphotypes were obtained from tomato fruit rot. The results showed that the prevalence of this disease was significantly higher and identical in all localities covered by the study according to the Duncan test at $\mathrm{P} \leq 0.05$. Fruits from these basins contained nine morphotypes of Fusarium spp. of which the most frequent were F1DS morphotypes (16.92\%) from Dschang followed by F1BD (16.62\%) and F3BD (16.34\%) from Mbouda fruits and the least frequent was F3FBT from Foumbot. The study of the morpho-cultural characters of the different morphotypes of Fusarium spp. showed that the morphotypes F2DSC from Dschang, F1FBT, F3FBT from Foumbot, F1BD, F3BD and F4BD from Mbouda showed the greatest radial growth. Similarly, the morphotypes F2DSC from Dschang and F1BD from Mbouda showed the fastest growth rate, while the lowest growth rates were recorded with the F1DSC, F3DSC from Dschang and F2FBT from Foumbot. Foumbot's F3FBT and Mbouda's F1BD morphotypes showed the highest sporulation rate. On the other hand, the F3DSC morphotype of Dschang showed the lowest number of conidia.
\end{abstract}

\section{Introduction}

Tomato (Solanum lycopersicum L.) due to its high content of vitamins and antioxidants has an important place in human nutrition (Sravanthi and Gangadhar, 2015). In addition to these essential elements to human health, tomato fruits provide several phytochemical compounds such as carotenoids, terpenoids, 
phytosterols, flavonoids, indoles and fibers that help prevent certain pathologies such as cardiovascular diseases, cancers and degenerative diseases related to old age (Wojcik et al., 2010; Britt et al., 2011; Troncoso-Rojas et al., 2013). Tomato trade accounts for more than $17 \%$ of global trade in fruits and vegetables with a monetary value of more than $\$ 8.5$ billion (USAID, 2006). Global tomato production has steadily increased in recent years, from over 130 million tons in 2014 to 182,301 million tons in 2017 (FAO, 2019). In Cameroon, it has increased over the years, with a production of 14 thousand tons in 2005, it rose to 889,800 tons in 2012 (FAOSTAT, 2015), an increase of 866 thousand tons with the main production area being the Western region, particularly the Foumbot, Mbouda and Dschang basins (Rock, 2015). Despite this increase in production and the multiple virtues of the tomato, its production is confronted after harvest with many phytosanitary constraints including fungal rot which can cause losses of about 40 to $90 \%$ (Kutama et al., 2007; Ebimieowei et al., 2013, Benlamoudi et al. 2019). Among the fungal species responsible for the deterioration of tomato fruits are those belonging to the genus Fusarium responsible for Fusariosis (Mugao, 2010; Abu et al., 2013; Ayele et al., 2021). Fusarium species belonging to this genus are the most frequent pathogens on tomato fruits, causing leaf wilt and numerous rots of the different organs of tomato (Kavi et al., 2018). These pathogens cause brown to black discoloration of the fruit. Studies by Khedoudja et al. (2014) have shown that some Fusarium species can cause yield losses of up to $90 \%$. Nirmaladevi et al. (2016) reported that other species such as $F$. oxysporum were responsible for more than $80 \%$ of post-harvest rots in tomato fruits in India. Fusarium species involved in this rot contaminate tomato fruits with various mycotoxins (Wisniewka et al., 2011; Maja et al., 2012; Zainudin et al., 2015; Wamalwa et al., 2018; Srinivas et al., 2019). These secondary metabolites produced by fungi are known to be toxic to many organisms. They deteriorate the quality and quantity of fruits and severely limit their yield and marketing (Blancard, 2012). The variability of the different morphotypes of Fusarium spp. involved in this disease makes it difficult to diagnose the exact causes of enormous losses to farmers.

Knowledge of the morphotypes of Fusarium spp. will enable an efficient control method against this disease pre and post-harvest for sustainable management of tomato fruits. It is in this context that this work, whose objective is to determine the prevalence of Fusarium spp. in the major tomato fruit production basins in West Cameroon, to inventory and characterize the different morphotypes of Fusarium spp. associated with this tomato fruit rot, has been carried out.

\section{Materials and methods}

\section{Collection of tomato fruits}

The experiments were conducted in April 2018. Tomatoes fruits with symptoms of rot (secretion of white, orange, purple, pink, beige liquid depending on the species of Fusarium) were randomly collected in 15 different farms equally distributed in Dschang, Foumbot and Mbouda in the west region of Cameroon. In each farm, the median number of fruit collected was 50 . These fruits were packed into a sterile polyethylene bag lined with soft paper and then carried to the Plant Pathology and Agricultural Zoology Research Unit for fungi isolation and identification.

\section{Prevalence of fusariosis in tomato fruits}

The prevalence of Fusariosis in tomato fruits was determined from fruits collected from gardeners in the production basins of Dschang, Foumbot and Mbouda. For this purpose, three crates of tomato fruits (containing 350 fruits per crate, either a total of 1050 for the three crates) were randomly selected in each of these basins where the collection was made. These fruits contained in each crate were carefully observed on site for the presence of fruit browning, black canker; external blackish-black rot, reddish-black necrosis and underlying fruit pulp, brown to black discoloration of the fruit. These symptoms vary according to the Fusarium species involved in the disease. Fruits showing such symptoms were considered to be affected by Fusarium and were counted. The prevalence of the disease was determined according to the formula of Amata et al. (2009) and Onyeani et al. (2012):

Prevalence $(\%)=\frac{\text { Number of fruits inspected showing symptoms of the disease }}{\text { Total number of fruits inspected }} X 100$

\section{Isolation and identification of different Fusarium spp. associated with tomato fruits}

The tomato fruits showing symptoms of Fusarium were taken to the laboratory where they were first washed 
separately with tap water and then superficially disinfected with absorbent cotton soaked in $95 \%$ alcohol. Necrotic tissue fragments of about $2 \mathrm{~mm}^{2}$ were removed under a microbiological hood near a flame of a Bunsen burner using a sterile scalpel. These fragments were then disinfected in $95 \%$ ethanol for 1 minute, rinsed 3 times successively with distilled water to remove traces of the disinfectant and then placed on sterilized filter paper to remove excess water. These fragments were inoculated aseptically into $90 \mathrm{~mm}$ glass Petri dishes containing $20 \mathrm{ml}$ of the PDA medium in a ratio of 5 fragments per Petri dish and placed under dark conditions in an incubator at $24 \pm 2^{\circ} \mathrm{C}$. After daily observations, the visible fungal colonies around the inoculated fragments were collected and individually transferred into new Petri dishes containing PDA medium. After several replications, pure cultures of the different fungal isolates were obtained.

The identification of the isolated fungal species was made based on the morphological characteristics of the mycelium (septate or non-septate) and the fruiting bodies (conidia) observed under the light microscope using mycological identification keys (Barnett and Hunter, 1972). These observations have made it possible to calculate the isolation frequencies (FI) of the different Fusarium spp. according to the following formula (Keuete et al., 2015):

$$
\text { FI (\%) }=\frac{\text { Number of specific fungi isolated }}{\text { Total number of fungi isolated }} X 100
$$

After identification, the different Fusarium spp. obtained were sealed in Petri dishes with para-film paper and stored in the incubator at $18-20^{\circ} \mathrm{C}$ for testing. A summary of morphotypes of Fusarium spp. used in this study is listed in Table 1.

\section{Characterization of different morphotypes of Fusarium spp. associated with tomatoes}

Radial growth, appearance and pigmentation of Fusarium spp.

The morphological and cultural characteristics of the different Fusarium spp. have been described from 7day-old pure cultures. For this purpose, a mycelial explant of $0.4 \mathrm{~cm}$ diameter was taken from the growth front of each pure culture and deposited under a microbiological hood in the center of a Petri dish containing the PDA culture medium at a rate of 3 replications per isolate. Incubation took place in the dark at a temperature of $24 \pm 2{ }^{\circ} \mathrm{C}$ for 7 days. Observations were made daily at the same time. They focused on radial growth. Colony diameter was measured from two perpendicular axes drawn on the backs of the Petri dishes to determine radial growth.

$$
\text { Radial growth }(\mathrm{cm})=\frac{\mathrm{d} 1+\mathrm{d} 2}{2}-2 \mathrm{~d} 0
$$

Where: $\mathrm{d} 1$ and $\mathrm{d} 2=$ diameter of the radial growth in both directions, $\mathrm{d} 0=$ diameter of the die.

The growth rate ( $\mathrm{cm} /$ day) of each morphotype was calculated according to the formula of Sofi et al. (2013).

$$
\text { Growth rate }(\mathrm{cm} / \text { day })=
$$

Growth observed on particular day (cm)-Growth on previous observation (cm)

Observations on the appearance (cottony, fibrous and compact) and pigmentation (whitish, pinkish, greenish, greyish and yellowish) of the fungal colony of each morphotype were made on the 7 th day of culture.

Table 1. Different morphotypes of Fusarium spp. from three localities of the West region of Cameroon.

\begin{tabular}{ll}
\hline Morphotypes & Production basins \\
\hline F1DS & Dschang \\
F2DS & Dschang \\
F3DS & Dschang \\
F1BT & Foumbot \\
F2BT & Foumbot \\
F3BT & Foumbot \\
F1BD & Mbouda \\
F2BD & Mbouda \\
F4BD & Mbouda \\
\hline
\end{tabular}

\section{Size and shape of conidia of different Fusarium spp.}

Microscopic characterization was performed from pure cultures on PDA medium in an incubator at a temperature of $24 \pm 2{ }^{\circ} \mathrm{C}$ for 7 days in the dark. A mycelial fragment taken from the center of the culture using a lancet needle was deposited on a slide covered with a cotton blue drop and observed under a regular microscope at $400 \mathrm{X}$ magnification. These observations concerned the shape (cylindrical, fusiform, ovoid and oval) and size measurement (length and width) of the conidia. For each morphotype, 18 conidia were studied. The experiment was repeated three times (Djeugap et al., 2017). 


\section{Enumeration of conidia of different Fusarium spp.}

Pure fruiting cultures of each 7-day old Fusarium spp. were carefully brushed with a fine brush in $20 \mathrm{ml}$ of sterilized distilled water. The resulting conidial suspension was shaken with a vortex to release the conidia from the conidiophores, then this suspension was filtered (to remove mycelial fragments), then a drop of Tween 20 was added to homogenize the suspension and finally, the number of conidia/ml was estimated from a Thoma cell. This experiment was repeated three times (Tsopmbeng et al., 2012).

\section{Experimental design and statistical analysis}

All the experiments were conducted in a completely randomized design (CRD). The data of Radial growth, growth rate, sporulation rate and diameter growth were subjected to analysis of variance. The differences between means at $5 \%$ were determined by WallerDuncan's multiple range tests using the Statistical Package for the Social Science (SPSS 16.0) program. The experimental results were expressed (where necessary) as mean \pm standard deviation.

\section{Results}

\section{Prevalence of fusariosis of tomato fruits in West Cameroon}

Table 2 shows the prevalence of Fusariosis on tomato fruits according to production basins and years of harvest. The same prevalence of Fusariosis on tomato fruits was observed on fruits from all production basins during the two years of data collection. The same prevalence of Fusariosis was also observed each year on fruits from all three basins inspected.

\section{Inventory of the different Fusarium spp. associated with tomato fruit}

Distribution of the different Fusarium spp. isolated from fruits according to production basins

Table 3 presents the number of different Fusarium spp. from tomatoes from the three main production basins of the West region of Cameroon according to the basins and years. Overall, 361 isolates of Fusarium spp. were isolated from tomato fruits. These different Fusarium spp. isolates belong to 9 morphotypes. The number of isolates varied according to the production farms. The most represented Fusarium spp. morphotype was F1DSC from Dschang locality and consisted of 40 and 21 isolates respectively in 2017 and 2018 for a total of 61 isolates. The F3FB morphotype from the Foumbot basin was the least represented with 9 isolates in 2017 and 15 isolates in 2018 for a total of 24 isolates (Table 3 ).

Table 4 shows the frequency of appearance of the different morphotypes of Fusarium spp. associated with tomato fruit rot from the production basins of Dschang, Foumbot and Mbouda. The frequency of appearance of the different morphotypes of Fusarium spp. varied according to the production basins. The most frequent morphotypes are F1DS (16.92\%) from the Dschang basin followed by F1BD (16.62\%) and F3BD (16.34\%) from Mbouda fruits. The F3FBT morphotype from the Foumbot basin is the least frequent with a frequency of appearance of $06.65 \%$.

Table 2. Prevalence (\%) of fusariosis on tomato fruits.

\begin{tabular}{lll}
\hline Production basins & Year 2017 & Year 2018 \\
\hline Dschang & $38.27 \pm 11.12^{\mathrm{a}^{*}}$ & $29.09 \pm 00.83^{\mathrm{ab}}$ \\
Foumbot & $23.46 \pm 01.13^{\mathrm{b}}$ & $27.91 \pm 00.66^{\mathrm{b}}$ \\
Mbouda & $28.77 \pm 00.77^{\mathrm{ab}}$ & $30.18 \pm 00.61^{\mathrm{a}}$ \\
\hline
\end{tabular}

$\mathrm{a}$ and b: comparison of fruit prevalences over two years; *means affected by the same letter on the same line are not significantly different according to Duncan's test at $\mathrm{P} \leq 0.05$.

\section{Characterization of the different morphotypes of Fusarium spp.}

Appearance and pigmentation of the mycelium of the different morphotypes of Fusarium spp.

Based on the fusarium lesions observed on the different tomato fruits, variability in the fungal profile of the different Fusarium spp. was obtained on the PDA culture medium. The examination of these different Fusarium spp. was based on the pigmentation and appearance of the mycelial colony. These different Fusarium spp. isolated and identified belong to 9 morphotypes (Table 3). 
The fungi isolated in the three major tomato production basins of West Cameroon presented morphotypes with different aspects. The F1DSC, F2DSC and F3FBT morphotypes from the Dschang and Foumbot basins respectively, as well as the F3BD morphotypes from Mbouda, presented cottony mycelial colonies. The F2FBT morphotypes from the Foumbot basin showed a fibrous mycelia while the F1FBT morphotypes from the same basin showed a downy mycelium. The F1BD and F2BD morphotypes from Mbouda had a compact mycelium.

The observation of the pigmentation of the mycelium of the different Fusarium spp. of three major production basins in West Cameroon has shown the existence of three distinct groups. The first group consisting of the yellowish morphotype (F3DSC), the second group consisting of the pinkish morphotypes (F2BD) and the last group consisting of all the other morphotypes with whitish pigmentation (Table 5).

Table 3. The number of different Fusarium spp. according to production basins and years of isolation.

\begin{tabular}{lllll}
\hline $\begin{array}{l}\text { Production } \\
\text { basins }\end{array}$ & Morphotypes & $\begin{array}{l}\text { Year } \\
\mathbf{2 0 1 7}\end{array}$ & $\begin{array}{l}\text { Year } \\
\mathbf{2 0 1 8}\end{array}$ & Total \\
\hline Dschang & F1DS & 40 & 21 & 61 \\
& F2DS & 17 & 10 & 27 \\
& F3DS & 09 & 20 & 29 \\
Foumbot & F2FB & 22 & 19 & 41 \\
& F2FB & 14 & 11 & 25 \\
& F3FB & 09 & 15 & 24 \\
Mbouda & F1BD & 28 & 32 & 60 \\
& F2BD & 19 & 16 & 35 \\
& F3BD & 31 & 28 & 59 \\
& Total & 189 & 172 & 361 \\
\hline
\end{tabular}

Table 4. Frequency (\%) of appearance of the different morphotypes of Fusarium spp. in the three main production basins of West Cameroon.

\begin{tabular}{llll}
\hline $\begin{array}{l}\text { Production } \\
\text { basins }\end{array}$ & Morphotypes & $\begin{array}{l}\text { Number of } \\
\text { isolates }\end{array}$ & Frequency \\
\hline Dschang & F1DS & 61 & 16.90 \\
& F2DS & 27 & 07.48 \\
Foumbot & F3DS & 29 & 08.03 \\
& F1FB & 41 & 11.36 \\
& F2FB & 25 & 06.93 \\
Mbouda & F3FB & 24 & 06.65 \\
& F1BD & 60 & 16.62 \\
& F2BD & 35 & 09.70 \\
& F3BD & 59 & 16.34 \\
\hline
\end{tabular}

Table 5. Appearance, mycelial pigmentation and conidial shape of the different morphotypes of Fusarium spp.

\begin{tabular}{llll}
\hline $\begin{array}{l}\text { Morpho- } \\
\text { types }\end{array}$ & $\begin{array}{l}\text { Morphotypes } \\
\text { Code }\end{array}$ & $\begin{array}{l}\text { Appearance } \\
\text { of mycelium }\end{array}$ & $\begin{array}{l}\text { Colour of } \\
\text { mycelium }\end{array}$ \\
\hline 1 & F1DS & Cottony & White \\
2 & F2DS & Cottony & White \\
3 & F3DS & Ras mucous & Yellow \\
4 & F1FB & Fluffy & White \\
5 & F2FB & Fibrous & White \\
8 & F3FB & Cottony & White \\
7 & F1BD & Compact & White \\
8 & F2BD & Compact & Pink \\
9 & F3BD & Cottony & White \\
\hline
\end{tabular}

\section{Radial growth of the different morphotypes of Fusarium spp.}

Table 6 shows the radial growth of the different morphotypes of Fusarium spp. The different morphotypes showed a significant difference in radial growth of Fusarium spp. on tomato fruits from three major production basins in West Cameroon (Table 6). Thus, the radial growth of the different Fusarium spp. observed on day 7 of cultivation on PDA medium in the three production basins showed that the morphotypes F2DSC from Dschang, F1FBT and F3FBT from Foumbot fruits showed the greatest radial growth in 2017 and 2018. Similarly, except for the F2BD morphotype, all other morphotypes from Mbouda fruits showed the highest radial growth. These radial growths varied between 07.47 and $08.20 \mathrm{~cm}$ in both years. The other morphotypes showed radial growth that was essentially identical and significantly lower than the other morphotypes according to Duncan's 5\% test. The radial growth of these morphotypes ranged from 04.67 to $06.33 \mathrm{~cm}$.

\section{The growth rate of the different morphotypes of Fusarium spp.}

Table 7 shows the radial growth rate of Fusarium spp. The radial growth rate varied according to morphotype, production basin and year. In 2017 and 2018, isolates of F2DSC and F1BD morphotypes from the Dschang and Mbouda ponds, respectively, showed the fastest growth rate (between 0.87 and $0.91 \mathrm{~cm} /$ day). On the other hand, F1DSC, F3DSC and F2FBT morphotype isolate from Dschang and Foumbot showed the lowest radial growth rate $(0.37$ and $0.57 \mathrm{Cm} /$ day respectively for both years) according to the 5\% Duncan test (Fig. 1). 
Table 6. Radial growth of different morphotypes of Fusarium spp.

\begin{tabular}{llll}
\hline Production basins & Morphotypes & Year 2017 & Year 2018 \\
\hline Dschang & F1DSC & $05.77 \pm 01.10^{\mathrm{b}^{*}}$ & $06.04 \pm 00.53^{\mathrm{b}}$ \\
& F2DSC & $07.75 \pm 00.02^{\mathrm{a}}$ & $08.00 \pm 00.01^{\mathrm{a}}$ \\
Foumbot & F3DSC & $05.33 \pm 00.58^{\mathrm{b}}$ & $06.03 \pm 00.52^{\mathrm{b}}$ \\
& F1FBT & $07.76 \pm 00.02^{\mathrm{a}}$ & $08.02 \pm 00.00^{\mathrm{a}}$ \\
& F2FBT & $04.67 \pm 01.15^{\mathrm{b}}$ & $05.67 \pm 00.58^{\mathrm{b}}$ \\
Mbouda & F3FBT & $07.47 \pm 00.06^{\mathrm{a}}$ & $08.00 \pm 00.01^{\mathrm{a}}$ \\
& F1BD & $07.60 \pm 00.53^{\mathrm{a}}$ & $08.01 \pm 00.01^{\mathrm{a}}$ \\
& F2BD & $05.33 \pm 00.58^{\mathrm{b}}$ & $06.33 \pm 00.58^{\mathrm{b}}$ \\
\hline
\end{tabular}

*Means columns followed by the same letter are not significantly different by Duncan's Multiple Range test $5 \%$ at a probability level.

Table 7. The growth rate of the different morphotypes of Fusarium spp.

\begin{tabular}{llll}
\hline Production basins & Morphotypes & Year 2017 & Year 2018 \\
\hline Dschang & F1DSC & $00.37 \pm 00.06^{\mathrm{c}^{*}}$ & $00.47 \pm 00.06^{\mathrm{c}}$ \\
& F2DSC & $00.88 \pm 00,06^{\mathrm{a}}$ & $00.91 \pm 00.09^{\mathrm{a}}$ \\
Foumbot & F3DSC & $00.43 \pm 00.12^{\mathrm{c}}$ & $00.53 \pm 00.12^{\mathrm{c}}$ \\
& F1FBT & $00.76 \pm 00.02^{\mathrm{b}}$ & $00.77 \pm 00.01^{\mathrm{b}}$ \\
& F2FBT & $00.43 \pm 00.06^{\mathrm{c}}$ & $00.57 \pm 00.06^{\mathrm{c}}$ \\
Mbouda & F3FBT & $00.76 \pm 00.01^{\mathrm{b}}$ & $00.76 \pm 00.02^{\mathrm{b}}$ \\
& F1BD & $00.87 \pm 00.06^{\mathrm{a}}$ & $00.91 \pm 00.00^{\mathrm{a}}$ \\
& F2BD & $00.76 \pm 00.01^{\mathrm{b}}$ & $00.76 \pm 00.02^{\mathrm{b}}$ \\
\hline
\end{tabular}

*Means columns followed by the same letter are not significantly different by Duncan's Multiple Range test $5 \%$ at a probability level.

\section{Size of the conidia of the different morphotypes of Fusarium spp.}

Table 8 shows the variation in size (length and width of conidia at day 7 of the culture on PDA medium. Conidial size varied according to morphotype, production basin and year of data collection. In 2017 and 2018, the F1FBT and F3BD morphotypes from the Foumbot and Mbouda basins respectively showed macroconidia of identical lengths according to the Duncan 5\% test (ranging from 54.1 to $39.36 \mu \mathrm{m}$ ).

These lengths are significantly longer than those of the other morphotypes. The shortest lengths of macroconidia were noted with the F2FBT morphotype from Foumbot tomato fruits (13.43 and $14.43 \mu \mathrm{m}$ respectively for both years). On the other hand, the F4FBBT morphotype on tomato fruits from the same production basin showed no macroconidia. Morphotypes F2DSC, F3DSC from Dschang and F1BD from Mbouda showed macroconidia of intermediate lengths ranging from 20.81 to $23.65 \mu \mathrm{m}$. Concerning their widths, the F1DSC, F3DSC morphotypes from
Dschang and F2FBT from Foumbot presented identical widths in 2017 and 2018. Similarly, these widths are similar to those of the F3BD morphotype isolated from tomato fruits from Mbouda in 2018. These widths were the highest according to Duncan's test at 5\% and varied between 4.19 and $5.22 \mu \mathrm{m}$. The lowest widths were recorded with the F2DSC morphotype from Dschang $(2.14$ and $2.18 \mu \mathrm{m})$ in both years while F1FBT and F3FBT morphotypes showed intermediate widths in 2017 and 2018 as did the F3BD morphotype in 2018.

In terms of microconidia, Foumbot's F3FBT presented the longest microconidia lengths in 2017 and 2018. These microconidia showed lengths of 25.57 and 25.90 $\mu \mathrm{m}$ respectively for both years. On the other hand, the F2BD morphotype from Mbouda, which does not have macroconidia, showed microconidia of short lengths, as did the F2DSC morphotypes from the Dschang locality. The F3FBT morphotypes in 2017 and 2018 had the highest microconidia widths while the lowest width was recorded with the F2DSC morphotype. The other morphotypes presented overall intermediate values according to Duncan's 5\% test. 

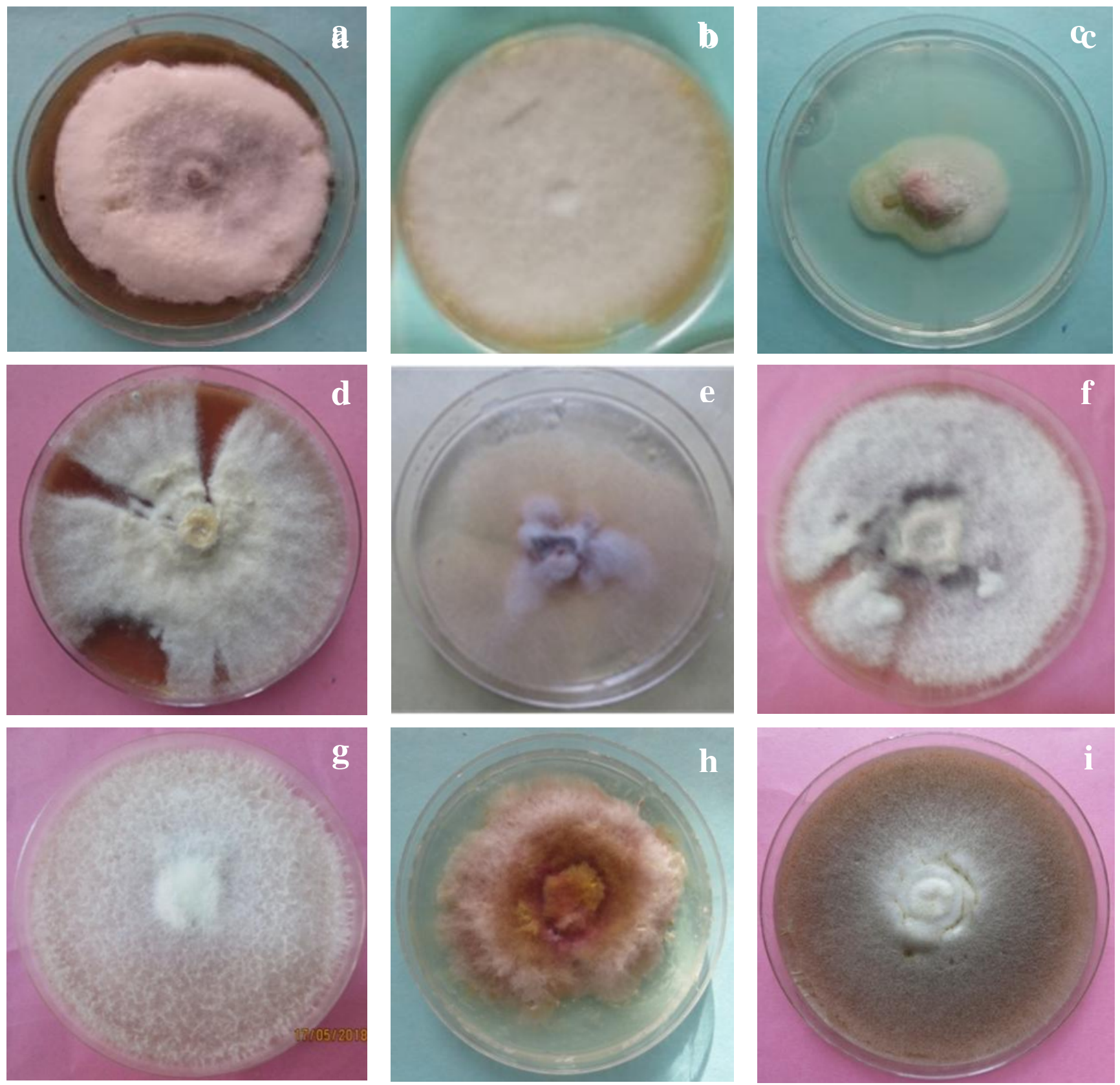

Fig. 1: Colonies of Fusarium species on PDA medium (a)pure culture of F1DSC; (b) pure culture of F2DSC; (c) pure culture of F3DSC; (d) pure culture of F1FBT; (e) pure culture of F2FBT; (f) pure culture of F3FBT; (g) pure culture of F1BD; (h) pure culture of F2BD; (i) pure culture of F3BD.

\section{Quantification of the sporulation of the different morphotypes of Fusarium spp.}

Table 9 shows the variation in the number of conidia produced on day 10 by the different Fusarium spp. as a function of the year, production basin and morphotype. In 2017 and 2018, morphotypes F3FBT and F1BD from the Foumbot and Mbouda basins respectively showed the highest sporulation rate $\left(25.25 \times 10^{6} ; 26.25 \times 10^{6}\right.$ and $25.25 \times 10^{6} ; 26.26 \times 10^{6}$ conidia/ml respectively). In 2018 the F2BD morphotype of Mbouda showed the same high sporulation rate as the previous ones. On the other hand, the other morphotypes presented the lowest number of conidia (Fig. 2). 
Table 8. Size of conidia of the different morphotypes of Fusarium spp. studied.

\begin{tabular}{|c|c|c|c|c|c|}
\hline \multirow{3}{*}{$\begin{array}{l}\text { Production } \\
\text { basins }\end{array}$} & \multirow[t]{3}{*}{ Morphotypes } & \multicolumn{4}{|c|}{ Conidial size $(\mu \mathrm{m})$ after 7 days } \\
\hline & & \multicolumn{2}{|l|}{ Macroconidia } & \multicolumn{2}{|l|}{ Microconidia } \\
\hline & & Mean length $(L)$ & Mean width (I) & Mean length $(L)$ & Mean width (l) \\
\hline & Year 2017 & & & & \\
\hline \multirow[t]{3}{*}{ Dschang } & F1DS & $38.47 \pm 0.01^{\mathrm{b}^{*}}$ & $04.89 \pm 00.01^{\mathrm{a}}$ & $04.88 \pm 00.01^{\mathrm{d}}$ & $02.21 \pm 00.02^{\mathrm{b}}$ \\
\hline & F2DS & $20.81 \pm 0.01^{\mathrm{c}}$ & $02.14 \pm 00.02^{\mathrm{c}}$ & $02.86 \pm 00.01^{\mathrm{e}}$ & $01.03 \pm 0.01^{\mathrm{c}}$ \\
\hline & F3DS & $21.85 \pm 00.02^{\mathrm{c}}$ & $04.67 \pm 00.01^{\mathrm{a}}$ & $04.96 \pm 00.01^{\mathrm{d}}$ & $02.24 \pm 0.01^{\mathrm{b}}$ \\
\hline \multirow[t]{3}{*}{ Foumbot } & F1FB & $53.7 \pm 00.01^{\mathrm{a}}$ & $03.27 \pm 00.01^{\mathrm{b}}$ & $09.86 \pm 01,02^{\mathrm{c}}$ & $02.32 \pm 0.01^{\mathrm{b}}$ \\
\hline & $\mathrm{F} 2 \mathrm{FB}$ & $13.43 \pm 00.02^{\mathrm{d}}$ & $04.19 \pm 00.02^{\mathrm{a}}$ & $04.86 \pm 00.02^{\mathrm{d}}$ & $02.22 \pm 0.03^{\mathrm{b}}$ \\
\hline & F3FB & $49.26 \pm 00.01^{\mathrm{a}}$ & $03.12 \pm 00.01^{\mathrm{b}}$ & $25.57 \pm 03.04^{\mathrm{a}}$ & $03.32 \pm 0.01^{\mathrm{a}}$ \\
\hline \multirow[t]{4}{*}{ Mbouda } & F1BD & $22.78 \pm 0.01^{\mathrm{c}}$ & $04.65 \pm 00.01^{\mathrm{a}}$ & $04.87 \pm 00.01^{\mathrm{d}}$ & $02.25 \pm 0.01^{\mathrm{b}}$ \\
\hline & F2BD & / & l & $06.21 \pm 00.02^{\mathrm{d}}$ & $02.68 \pm 0.01^{\mathrm{b}}$ \\
\hline & F3BD & $39.36 \pm 0.01^{\mathrm{b}}$ & $03.24 \pm 00.02^{b}$ & $14.21 \pm 04.07^{\mathrm{b}}$ & $02.21 \pm 0.02^{\mathrm{b}}$ \\
\hline & Year 2018 & & & & \\
\hline \multirow[t]{3}{*}{ Dschang } & F1DS & $39.51 \pm 00.01^{b}$ & $05.22 \pm 00.02^{\mathrm{a}}$ & $05.86 \pm 00.01^{\mathrm{d}}$ & $03.21 \pm 00.01^{\mathrm{b}}$ \\
\hline & F2DS & $21.81 \pm 00.01^{\mathrm{c}}$ & $02.81 \pm 00.01^{\mathrm{c}}$ & $03.86 \pm 00.01^{\mathrm{e}}$ & $02.03 \pm 00.01^{\mathrm{c}}$ \\
\hline & F3DS & $22.86 \pm 00.01^{c}$ & $04.67 \pm 00.02^{\mathrm{a}}$ & $05.96 \pm 00.02^{\mathrm{d}}$ & $03.23 \pm 00.02^{\mathrm{b}}$ \\
\hline \multirow[t]{3}{*}{ Foumbot } & F1FB & $54.01 \pm 01.21^{\mathrm{a}}$ & $03.27 \pm 00.01^{\mathrm{b}}$ & $10.86 \pm 03.00^{c}$ & $03.22 \pm 00.01^{\mathrm{b}}$ \\
\hline & $\mathrm{F} 2 \mathrm{FB}$ & $14.43 \pm 00.01^{\mathrm{d}}$ & $04.43 \pm 00.01^{\mathrm{a}}$ & $05.86 \pm 00.01^{\mathrm{d}}$ & $03.22 \pm 00.02^{\mathrm{b}}$ \\
\hline & F3FB & $49.59 \pm 00.57^{\mathrm{a}}$ & $03.26 \pm 00.02^{b}$ & $25.90 \pm 01.15^{\mathrm{a}}$ & $04.32 \pm 00.01^{\mathrm{a}}$ \\
\hline \multirow[t]{3}{*}{ Mbouda } & F1BD & $23.65 \pm 00.01^{\mathrm{c}}$ & $04.79 \pm 00.01^{\mathrm{a}}$ & $05.86 \pm 00.01^{\mathrm{d}}$ & $03,25 \pm 00.02^{\mathrm{b}}$ \\
\hline & F2BD & / & I & $07.21 \pm 00.01^{\mathrm{d}}$ & $03.68 \pm 00.01^{\mathrm{b}}$ \\
\hline & F3BD & $40.03 \pm 00.57^{\mathrm{a}}$ & $04.5 \pm 00.02^{\mathrm{a}}$ & $15.21 \pm 00.04^{\mathrm{b}}$ & $03.21 \pm 00.01^{\mathrm{b}}$ \\
\hline
\end{tabular}

*Means columns followed by the same letter are not significantly different by Duncan's Multiple Range test $5 \%$ at a probability level.

Table 9. Sporulation rate $\left(10^{6}\right.$ conidia/ml $)$ of the different morphotypes of Fusarium spp. from the different tomato production basins of West Cameroon.

\begin{tabular}{llll}
\hline Production basins & Morphotypes & Year 2017 & Year 2018 \\
\hline Dschang & F1DSC & $05.75 \pm 00.01^{\mathrm{e}^{*}}$ & $06.75 \pm 00.01^{\mathrm{d}}$ \\
& F2DSC & $10.75 \pm 00.01^{\mathrm{d}}$ & $11.75 \pm 00.01^{\mathrm{c}}$ \\
& F3DSC & $05.51 \pm 00.20^{\mathrm{e}}$ & $06.58 \pm 00.14^{\mathrm{e}}$ \\
Foumbot & F1FBT & $05.75 \pm 00.01^{\mathrm{e}}$ & $06.76 \pm 00.00^{\mathrm{d}}$ \\
& F2FBT & $21.75 \pm 00.02^{\mathrm{c}}$ & $22.76 \pm 00.01^{\mathrm{b}}$ \\
& F3FBT & $25.25 \pm 00.02^{\mathrm{a}}$ & $26.25 \pm 00.02^{\mathrm{a}}$ \\
Mbouda & F1BD & $25.25 \pm 00.01^{\mathrm{a}}$ & $26.26 \pm 00.01^{\mathrm{a}}$ \\
& F2BD & $24.58 \pm 00.58^{\mathrm{b}}$ & $26.24 \pm 00.01^{\mathrm{a}}$ \\
& F3BD & $10.75 \pm 00.00^{\mathrm{d}}$ & $11.76 \pm 00.01^{\mathrm{c}}$ \\
\hline
\end{tabular}

* Means affected by the same superscript letter in the same column are not significantly different according to Ducan's multiple tests at $\mathrm{P} \leq 0.05$.

\section{Discussion}

Fusariosis caused by fungal species belonging to the genus Fusarium is a real problem on tomatoes fruit production in the West region of Cameroon. This was more noticeable through the high prevalence of Fusariosis on tomato fruits observed in the three localities. This prevalence was identical in all localities. This similarity could be because all three localities belong to the same agro-ecological zone, which is that 
of the Western Highlands. Indeed, their climate is of humid tropical type (OMD, 2010). Temperatures vary between $15^{\circ}$ and $30^{\circ} \mathrm{C}$, an average of $25^{\circ} \mathrm{C}$ and relative humidity in these localities varies between 49 and $97 \%$ (Olivry, 2012). These temperatures and relative humidity would be at the origin of the germination of Fusarium spp. conidia observed as they are close to those favorable to the optimal development of the fungal species responsible for tomato fruit rots. Similar results were reported in Bangladesh by Begum and Momin (2000) who showed that fungi grow better in humid regions. The work of Kader (2002) reported that high humidity promotes the growth of tomato fruit rot fungi.

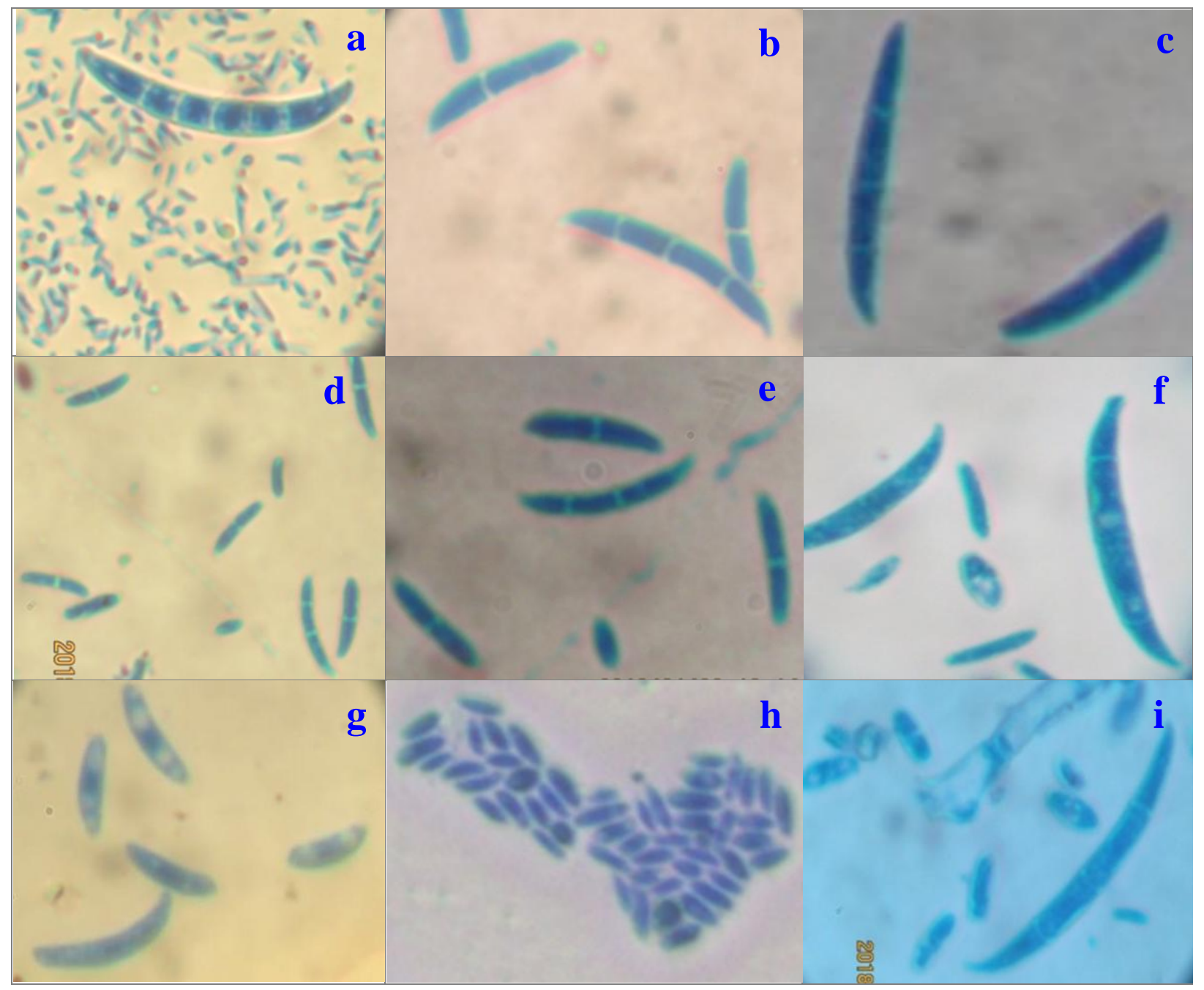

Fig. 2: Morphologies of Fusarium spp. isolated from tomato fruits of different localities in the West region of Cameroon as seen in the 400X optical microscope (a) F1DSC; (b) F2DSC; (c) F3DSC; (d) F1FBT; (e) F2FBT; (f) F3FBT, (g) F1BD; (h) F2BD; (i) F3BD.

The inventory of the different Fusarium spp. associated with tomato fruit rot showed that these Fusarium spp. belong to nine morphotypes. Besides, several studies have shown that Fusarium spp. cause fusariosis of many fruits (Benaouali, 2015, Rajendran et al., 2018; Benlamoudi et al., 2019). The morphotypes F1DS followed by F1BD and F3BD were the most frequent in all localities compared to the other morphotypes. The high frequency of these morphotypes could be since they are the most involved in the distribution of fusarium and cause important pre and post-harvest losses. On the other hand, the F3FBT morphotype was 
the least frequent. This low frequency could be explained by the fact that this morphotype would affect less the fruits and would have a negligible impact on the quality of these fruits. This difference in frequency of isolation of different Fusarium morphotypes has been reported in other works such as those of Kouakou et al. (2017) in Côte d'Ivoire on the inventory of post-harvest pathogenic fungi and evaluation of their sensitivity to azoxystrobin which reported that species of the genus Fusarium were isolated at variable frequencies from different fruits.

The results obtained on the characterization of Fusarium spp. showed a variation in the colors and morphotype aspects. The colors vary from white to yellow through pink. Some of these colors are in agreement with those observed by Beonuali (2015) in his work on the biodiversity of Fusarium oxysporium. Similarly, the morphotypes obtained are partly similar to those observed by Tshilenge et al. (2004) in their work on the characterization of Fusarium spp. associated with the decline of Robusta coffee in the Democratic Republic of Congo. This difference in pigmentation and morphotypes may be due to the nature and origin of different morphotypes. Indeed, Sedra (1993) has shown that the origin of morphotypes is a determining factor in the variability of crop morphology. This crop morphology can be affected by the age of the fungal strain. Thus, in this study, we also observed that pigmentation disappears with the aging of the strain but given the experimentation set up, it is not possible to say if this loss is definitive or not. Our observations agree with those of Henni et al. (1994) who in their work on morphological variability in Fusarium oxysporium showed that the age of the fungal strain influences its color.

Differences were observed between the radial growth of isolates from the same locality and those from different localities. This difference made it possible to group the isolates into two distinct categories. The F1FBT, F3FBT, F1BD and F3BD morphotypes form a fastgrowing group while the F1DSC, F3DSC, F2FBT and F2BD morphotypes form a slow-growing group. These radial growths revealed values for some morphotypes that are in the range of those already described by other authors (Tshilenge et al., 2004; Lombard et al., 2019).

The identification of the different isolates was done by light microscope using the identification guides of Barnett and Hunter (1972) and Leslie and Summurell
(2006). Following this observation, the mycelia appear with two types of conidia: microconidia isolated or agglomerated in false heads and macroconidia of variable size with 3 to 4 partitions. Previous work by Guezlane (1976) and Agrios (2005) has shown that some Fusarium oxysporium isolates from cereals have transversely partitioned macroconidia (triseptate) and microconidia which are small spores agglomerated in false heads.

From the sporulation point of view, all morphotypes sporulated differently but F3FBT and F1BD isolates showed the highest sporulation rates. This variation in sporulation can be attributed to the intrinsic and physicochemical factors of each isolate. Little information exists on the sporulation rate of species of the genus Fusarium because in microscopy many authors are not interested in this aspect yet very important for the characterization of a fungal species to better understand its ecology.

The variability within a morphological group shows that identification based only on morphological and cultural characteristics can lead to misidentification since morphological and cultural characteristics are easily influenced by environmental factors such as humidity, temperature and precipitation (Nadjet, 2010; Bhavya et al., 2019). However, according to Henni et al. (1994), although mycelial growth is not a stable criterion for differentiation of Fusarium spp. it is believed to play an important role in species variability.

\section{Conclusion}

This work has highlighted the existence of several morphotypes of Fusarium spp. on tomato fruits found in large production basins in the West region of Cameroon. Through the macroscopic study of isolates, nine morphotypes with higher variability of pigmentation were found. Microconidia and macroconidia of various sizes were identified after microscopic observation of these morphotypes. Given the profile of the different morphotypes of Fusarium spp. known, it would be wise to consider a means of controlling these morphotypes which cause many rots to reduce the losses of tomato fruits caused by them.

\section{Conflict of interest statement}

Authors declare that they have no conflict of interest. 


\section{Acknowledgement}

The authors are thankful to Laboratory of Phytopathology and Agricultural Zoology (LAPHYZA), University of Dschang, Cameroon for Providing Laboratory Facilities and gratefully acknowledged the friendly collaboration of the members of this laboratory as well as its staff.

\section{References}

Abu Bakar, A.I., Nur Ain Izzati, M. Z., Umi Kalsom, Y., 2013. Diversity of Fusarium species associated with post-harvest fruit rot disease of tomato. Sains Malaysiana, 42(7): 911-920.

Agrios G.N., 2005. Plant Pathology. Elsevier Academic Press, Amsterdam (5th Edn), pp.398-401.

Amata, R. L., Erbaugh, M., Miller, S., Otipa, M.J., Thuranira, E.G., Wabule, M., Waiganjo, M., 2009. Incidence, prevalence and severity of passion fruit fungal diseases in major production regions of Kenya. J. Appl. Biosci., 20(1): 1146-1152.

Ayele, M. T., Gebremariam, D. G., Patharajan, S., 2021. Isolation, identification and in vitro test for the biocontrol potential of Trichoderma viride on Fusarium oxysporium. Agric. J., 15(1): 18-33.

Barnett, H. L., Hunter, B. B., 1972. Illustrated Genera of Imperfect Fungi. Mineapolis: Burgress Publishing Company, Minneapolis MN, 241p.

Begum, H. A., Momin, A., 2000. Comparison between two detection techniques of seed borne pathogen in cucurbits in Bangladesh. Pak. J. Scient. Indust. Res., 43(4): 244-248.

Benaouali, H., 2015. La biodiversité des Fusarium oxysporium. Thèse de Doctorat en Microbiologie. Université d'Oren-Senia, pp.1-106.

Benlamoudi, W., Lakhdari, W., Dehliz, A., Guezoul, O., 2019. Experimental approach for easy identify Fusarium wilt of tomato. World J. Environ. Biosci., 8(2): 44-48.

Beonuali, H., 2015. La biodiversité des Fusarium oxysporum radicis lycopersici, Thèse de Doctorat de l'Université d'Oran Es-Senia, Algerie, pp.1-119.

Bhavya, R., Thammaiah, N., Devappa, V., Indiresh, K.M., Jayappa, J., 2019. Physiological studies of Fusarium oxysporium f.sp. melonis. Int. J. Curr. Microbiol. Appl. Sci., 8(11): 536-544.

Blancard, D., Laterrot, H., Marchoux, G., Candresse, T., 2012. A Colour Handbook-Tomato Diseases: Identification, Biology and Control. Manson Publishing Ltd., 688p.
Britt, B.F., Kristin, R., 2011. Tomato consumption and health: Emerging benefits. Amer. J. Lifestyle Med., 5(2): 182-191.

Djeugap, J. F., Daniel, D., Louis, B., 2017. Influence of culture media and temperature on growth and sporulation of Lasiodiplodia theobromae, Pestalotiopsis microspora and Fusarium oxysporum isolated from Ricinodendron heudelotii in Cameroon. Int. J. Curr. Microbiol. Appl. Sci., 6(6): 3098-3112.

Ebimieowei, E., Nwauzoma, A. B., Bawo, D. D. S., 2013. Postharvest spoilage of tomato and control strategies in Nigeria. J. Biol. Agric. Healthcare, 10(3): 1-12.

FAO, 2019. Étude diagnostique de la réduction des pertes après récolte de trois cultures: manioc tomate -pomme de terre. Rapport de synthèse: Cameroun, pp.1-90.

FAOSTAT, 2015. Food and Agriculture Organization of the United Nations Statistics. Division. Accessed on http://faostat.fao.org/site/567/default\#ancor

Guezlan, 1976. Essai de caractérisation enzymatique de Fusarium oxysporium par électrophorèse catabolisme auxinique et virulence chez deux isolats de Fusarium oxysporium f.sp dianthi. Thèse de Doctorat, faculté des sciences de l'Université de Maix Marseille II, France, pp.1-117.

Henni J., Boisso C. et Geige J.P., 1994. Variabilité de la morphologie chez Fusarium oxysporum f. sp. lycopersici. Plzytopath. Medit., 33: 51-58.

Kader, A. A. (Ed.), 2002. Post-harvest technology of horticultural crops. Oakland: University of California, Division of Agriculture and Natural Resources Publication, pp.3311-535.

Kavi Sidharthan, V., Rashmi, A., Surenthiran, N., Shanmugam,V., 2018. Selection and characterization of the virulent Fusarium oxysporum f. sp. lycopersici isolate inciting vascular wilt of tomato. Int. J. Curr. Microbiol. Appl. Sci., 7(2): 1749-1756.

Keuete, K. E., Tsopmbeng, N. G. R., Yaouba, A., Djeugap, F. J., Signaboubo, S., 2015. Antifungal potential of some plant extracts against three postharvest fungal pathogens of avocado (Persea americana Mill.) fruits. Int. J. Multidiscipl. Res. Develop., 2(4): 148-152.

Khedoudja, K., Bouziane, A., Mohamed, L. B., Fatima, Z. B., Bakhta, M., 2014. Etude de l'efficacité de l'extrait éthanoïque d'écorces de Punicagranatum sur deux souches phytopathogènes. Eur. Scient. J., 12(10), 1857-7881.

Kouakou, T. K., Thérese, A. A., Eric-Olivier, T., N'sou, 
I. L. V. O., 2017. Inventaire des champignons pathogens post-récoltes de la banane dessert et évaluation de leur sensibilité à l'azoxystrobine en Cote d'Ivoire. Eur. Scient. J., 21(13): 1-18.

Kutama, A. S., Aliyu, B. S., Mohammed, I., 2007. Fungal pathogens associated with tomato wicker baskets. South West J., 2(1), 38-39.

Leslie, J. F., Summerell, B. A., 2006. The Fusarium Laboratory Manual. Blackwell Publishing, Ames, IA, 21p.

Lombard, L., Sandoval, D. M., Lamprecht, S. C., Crous, P. W., 2019. Epitypification of Fusarium oxysporum clearing the taxonomic chaos. Persoonia, 43: 1-47.

Maja, I., Dragana, M., Zorica, N., Jelica, G. V., Dusica, J., Gordana, Z., 2012. Fusarium oxysporium as causal agent of tomato wilt and fruit rot. Pestic. Phytomed. (Belgrade), 27(1): 25-31.

Mugao, G. L., 2015. Tomato post-harvest spoilage causes and use of selected botanical extracts in their management in Mwea, Kirinyaga country. MSc. Thesis Kenyatta University, 109p.

Nadjet, B., 2010. Biodiversité fongique du sable de quatre plages du Littoral Ouest Algérien. Thèse de Master de 1'Université d'Oran, Algérie, pp.1-190.

Nirmaladevi, D., Venkataramana, M., Srivastava, R. K., Uppalapati, S. R., Gupta, V. K., Yli-Mattila, T., Chandra, N. S., 2016. Molecular phylogeny, pathogenicity and toxigenicity of Fusarium oxysporum f.sp. lycopersici. Sci. Rep., 6(1): 21-32.

Olivry, J. C., 2012. Le milieu physique de la région de l'Ouest, le bassin de la Mifi-sud: généralités et données de base. Tome 1, 285p.

OMD, 2010. Rapport Régional de progrès des Objectifs du Millénaire pour le Développement.

Onyeani, C. A., Osunlaja, S., Oworu, O. O., Olufemi, S., 2012. First report of fruit anthracnose in mango caused by Colletotrichum gloeosporioides in South Western Nigeria. Int. J. Scient. Technol. Res., 4: 3034.

Rajendran, M., Sankarasubramanian, H., Gandhi, K., Thiruvengadam, R., 2018. Comparative proteomic analysis of different isolates of Fusarium oxysporium lycopersici to exploit the differentially expressed proteins responsible for virulence on tomato plants. Front. Microbiol., 9: 420-423.

Rock Giguere, 2015. La culture de la tomate au Cameroun, htt://www.domainejoly.com/fr/nouvelles/ 2015/01/08/la-culture -de- la tomate-au-Cameroun/ consulté le 19 Février 2018.

Sedra, 1993. Caractérisation morphologique et culturale de Fusarium oxysporum $\mathrm{f}$.sp. albedinis, agent de la fusariose vasculaire (bayoud) du palmier dattier. Alawamta, 83(12): 209-222.

Sofi, T.A., Muzafer, A., Beig, G.H., Hassan, D., Mushtaq, A., Flaq, H.A, Ahangar, F.A., Padder, B.A., Shah, M.D., 2013. Cultural, morphological, pathogenic and molecular characterization of Alternaria mali associated with Alternaria leaf blotch of apple. Afr. J. Biotechnol., 12(4): 370-381.

Sravanthi, J., Gangadhar, S. R., 2015. Phytochemical and antioxidant composition in Lycopersicum esculentum. J. Med. Plants Stud., 3(4): 107-110.

Srinivas, C., Nirmala, D.D., Narasimha, K.M., Chakrabhavi, D.M., Lakshmeesha, T.R., Bhimpratap, S., Naveen, K.K., Niranjana, S.R., Abeer, H., Abdulaziz, A. A., Baby, T., Elsayed, F.A.A., Chandra, S.N., Rakesh, K.S., 2019. Fusarium oxysporum causal agent of vascular wilt disease of tomato: Biology to diversity. Saudi J. Biol. Sci., 26: 1315-1324.

Troncoso-Rojas, R., Sánchez-Estrada, A., Carvallo, T., González-León, A., Ojeda-Contreras, J., AguilarValenzuela, A., Tiznado-Hernández, M., 2013. A fungal elicitor enhances the resistances of tomato fruit to Fusarium oxysporum infection by activating the phenylpropanoid metabolic pathway. Phytoparasitica, 41(2): 133-142.

Tshilenge-Djim, P.L., Munaut, F., Kalonji-Mbuyi, A., Maraite, H., 2004. Caractérisation des Fusarium spp. associées au dépérissement du caféier Robusta en République Démocratique du Congo. Parasitica, 60(3-4): 19-34.

Tsopmbeng, G. R., Fontem, D.A., Yamde, K.F., 2012. Evaluation of culture media for growth and sporulation of Phythothora colocasiae Racib, causal agent of taro leaf blight. Int. J. Biol. Chem. Sci., 6(4): 1566-1573.

USAID, 2006. La filière tomate cerise en Guinée: situation actuelle et perspective de développement des exportations en Guinée. Rapport Final. Chemonics International Inc., Guinée, 24p.

Wamalwa, E., Muoma, J., Muyekho, F.N., Wekesa, C., Ajanga, S., 2018. Genetic diversity of Fusarium oxysporium races associated with cowpea fields in Kakamega Country. Fungal Genomics Biol., 8(2): 1-7.

Wiśniewska, H., Basiński, T., Chełkowski, J., Perkowski, J., 2011. Fusarium sporotrichioides Sherb. toxins evaluated in cereal grain with Trichoderma harzianum. J. Plant Prot. Res., 51(2): 134-139. 
Wojcik, M., Burzynska-Pedziwiatr, I., Woznia, L.A., 2010. Review of natural and synthetic important for health and longevity. Curr. Med. Chem., 17(28): 3262-888.
Zainudin, N.A.I.M., Perumal, N., 2015. Mycotoxins production by Fusarium and Aspergillus species isolated from cornmeal. Int. J. Agric. Biol., 17 (3): 440-448.

\section{How to cite this article:}

Njimah Mfonmbouot, D., Tsopmbeng Noumbo, G. R., Lacmata Tamekou, S., Keuete Kamdoum, E., Kuiate, J. R., 2021. Prevalence, inventory and characterization of different morphotypes of Fusarium spp. associated with spoilage of tomato fruits (Solanum lycopersicum L.) in the west-region of Cameroon. Int. J. Curr. Res. Biosci. Plant Biol., 8(1): 1-13. doi: https://doi.org/10.20546/ijcrbp.2021.801.001 